\title{
Editorial
}

\section{Teach aesthetic plastic surgery in medical colleges}

f I ask you to put your hand on your heart and say whether your plastic surgery training program in India trained you well enough to practice aesthetic surgery with the same ease, elegance, dexterity, and aplomb with which you treat cleft lip and palate, or perform a microvascular free latissimus dorsi flap or rehabilitate a post burn contracture hand, what will be your answer? Please do not even bother to answer, or worse still, be valiantly defensive about your teachers or your institution. The fact is we are still not there. We are not teaching aesthetic plastic surgery well enough. The logical question that crops up next is "Why?" When our mission should have been to push the frontiers of this sub- specialty of plastic surgery through patient care, clinical and laboratory research, and education of the next generation of plastic surgeons towards excellence, just as we have done with other aspects of plastic surgery, why have we failed to deliver here?

Aesthetic plastic surgery is a rapidly enlarging subspecialty that requires recognition in its own right. At present, a newly qualified, fully trained and accredited plastic surgeon hardly has any experience in aesthetic plastic surgery. Although surgeons are trained and experienced in carrying out reconstructive work, most of them do not have enough experience to carry out cosmetic work, such as breast augmentation or facial rejuvenation by lasers. This is because cosmetic surgery is typically carried out in private practice rather than in government teaching institutions, which remain flooded with reconstructive work and are invariably bursting in their seams. That is the reason why teachers of yesteryears thought it to be too frivolous a thing to indulge in, as much more noble deeds like treating burns and congenital anomalies were always beckoning us.

\begin{tabular}{|l|l|}
\hline \multicolumn{3}{|c|}{ Access this article online } \\
\hline Quick Response Code: & Website: \\
\hline & www.ijps.org \\
\hline & Dol: \\
\hline
\end{tabular}

Times have changed and so should we and so should our training programme. In the world that we live in, if buying a new tag heuer watch or an Audi car gives pleasure to one who can afford, then why should he not opt for hair transplantation to get the same pleasure? If flaunting an expensive mink coat or a precious diamond is perfectly acceptable, then why is flaunting a face lift any different? In today's world, 'appearance' remains the last bastion of discrimination and the advantages of being beautiful, stronger and smarter is important in many work places and vital in traditional Indian arranged marriages. Younger workers are considered to require less sleep, learn more quickly, and be more energetic, enthusiastic and useful for organizations and conversely older workers risk being replaced by younger ones because of the notion that they are less able to learn and adapt to a rapidly changing technological environment. In this changed and fiercely competitive scenario, is the quest of everlasting youth frivolous?

The M.Ch / DNB Plastic Reconstructive and Aesthetic Surgery courses in our colleges and universities should aim to meet all the clinical, research, professional and educational requirements of surgeons continuing their professional development within this entire clinical field and not be dismissive of any part of the curriculum. The need of the hour is a training program integrated into the M.Ch / DNB curriculum that enables qualified plastic surgeons to gain full time experience in the field of cosmetic/aesthetic surgery, ensuring that they acquire the necessary knowledge and skills to become adept at undertaking these types of surgical procedures and provide them with the requisite depth of experience in this sub-specialty of plastic surgery. This will help them in developing their private practice in cosmetic surgery, giving them a reputable qualification and provide patients with an assurance that their surgeon is properly trained and competent and way ahead of his amateur competitors. Innovation, research and creativity should be fostered in order to enable surgeons to evaluate and influence training and practice, to improve service delivery and effect change. Every time a new sub-specialty 
has come up on the horizon, may it be microsurgery or cranio-facial surgery, plastic surgery departments have risen up to the challenge and conquered it. What stops us from doing the same with aesthetic surgery?

I propose that we include a list of aesthetic surgery topics in our curriculum and if these are not being routinely done in a particular teaching unit, then our training should be made multi-centric so that the trainees can be sent to units performing these procedures. If this means involving private accredited cosmetic surgery clinics in a public - private partnership, then so be it. The topics that come to my mind are:

Basic principles of aesthetic surgery of the face and neck Blepharoplasty and brow lift

Rhytidectomy

Ancillary / Non surgical procedures for facial rejuvenation Complications of facial aesthetic surgery and their management

Dermabrasion, chemical peel and collagen injection

Rhinoplasty

Aesthetic surgery of the ears

Hair transplantation

Aesthetic laser surgery

Anatomy, congenital and developmental breast anomalies

Augmentation and reduction mammoplasty

Basic principles in the management of complications

following augmentation mammoplasty

Hypermastia, ptosis

Management of patients with high-risk diseases of the breast

Post-mastectomy breast reconstruction

Nipple- Areolar Reconstruction

Gynecomastia

Total body contouring- the abdomen and hips, buttocks and thighs

Aspirative lipoplasty

I can understand the reluctance of the authorities towards spending tax payer's money on cosmetic procedures, but these patients can be asked to pay for these services, thereby subsidizing the costs for reconstructive procedures being conducted on the poor and deserving ones. The cosmetic surgery patients will need calmer and unrushed settings, separate operation theatre and theatre time and private wards, and for all this they should pay, but the cost should be so adjusted that it are far less than the market charges.

Every time a self styled cosmetologist or a dermatologist or a dentist posing as a cosmetic surgery expert flaunts his business with a glitzy professionally driven advertisement campaign, we cringe and cry foul. We lament that to become a plastic surgeon, we have to be dedicated and endure a long road of education, training and examinations; 5 years of MBBS, 3 years of general surgery training and then 3 years of plastic surgery residency. To call himself a "cosmetic surgeon", all it took this fellow is a weekend course on how to do a laser or a filler or botox or even liposuction. But the million dollar question is: Did your M.Ch programme teach you about lasers, liposuction, botox and fillers well enough to call yourself an expert in this field? Clinicians, even if they are qualified plastic surgeons are required to promote safe, ethical, efficacious aesthetic surgery for the public, by establishing and maintaining high standards for the education, examination and certification of plastic surgeons in aesthetic plastic surgery. So, at this stage, we need to put our own house in order and not be offensive to prowling predators.

\section{Surajit Bhattacharya}

Editor IJPS

E-mail: surajitbh@yahoo.co.in

How to cite this article: Bhattacharya S. Teach aesthetic plastic surgery in medical colleges. Indian J Plast Surg 2012;45:431-2. 